\title{
Plateros aragoneses en la Corte madrileña (siglos XVII-XIX)
}

\section{"Aragonese silversmiths in the Madrid Court (17th to 19th century)"}

\section{José Manuel Cruz Valdovinos ${ }^{1}$}

Recibido:12-06-2020

Aceptado: 28-08-2020

\section{Resumen}

Se presentan noticias de 59 plateros aragoneses que están documentados en Madrid, alcanzando muchos de ellos la aprobación como maestros. De varios se conocen piezas con su marca. La mayoría fueron plateros de oro que era una facultad menos desarrollada que la de plata en Zaragoza — de donde procede la mayoría de los relacionados - y en otras platerías de Aragón. Las noticias provienen sobre todo del archivo del Colegio Congregación de San Eloy de artífices plateros de Madrid.

Palabras clave: plateros de oro, de plata, filigraneros, maestro, mancebo, aprendiz, alcabala.

\section{Abstract}

This article presents news on 59 Aragonese silversmiths who have been documented in Madrid, many of whom achieved approval as master silversmiths. Of several of them are known pieces bearing their mark. Most of them were goldsmiths, which was a much less developed ability as compared to silver in Zaragoza - where most of the silversmiths dealt with came from - and in the rest of Aragon. The news presented come mainly from the San Eloy Congregation College of Madrid's silversmith artists.

Keywords: gold and silversmiths, filigree, masters, officials, apprentices, alcabala.

1 Universidad Complutense de Madrid. josemanuelcruzvaldovinos@ghis.ucm.es 


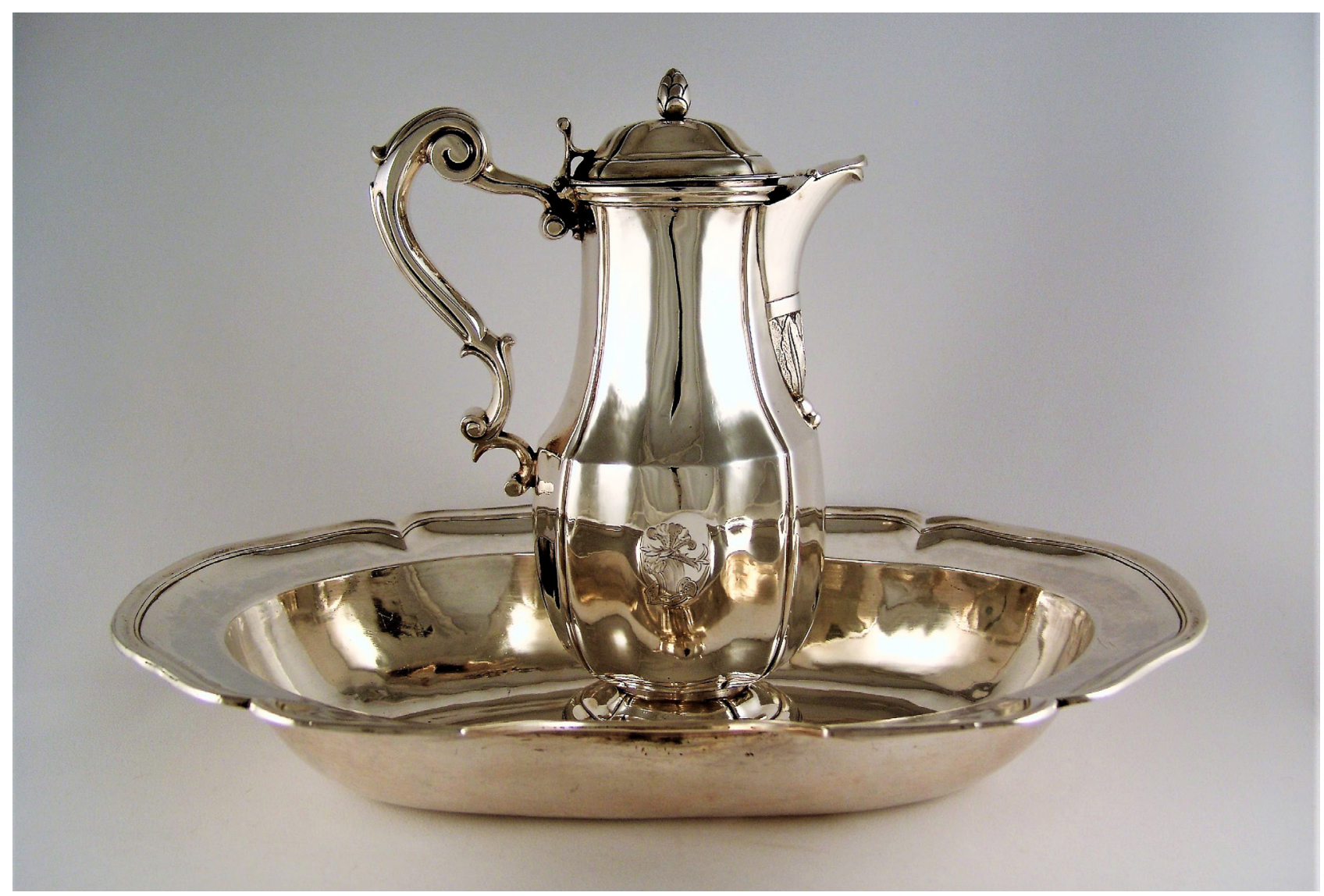

Fig. I: Pedro Luesma. Juego de aguamanil. I775/1780. Colección privada, Madrid.

Hemos reunido los plateros de origen aragonés que están documentados en Madrid durante los siglos XVII, XVIII y XIX. Como muchas veces y durante largos periodos no consta en la documentación y fuentes que hemos manejado el lugar de nacimiento, es posible que hubiera algunos más que los que mencionamos, pero nos atrevemos a asegurar que no serán muchos los que falten. No hemos incluido el siglo XVI porque, hasta el asentamiento de la Corte en Madrid en 1561 por voluntad de Felipe II, la Villa no fue un foco de atracción de artífices plateros, y, aunque lo fue después, los que fueron llegando procedían en su mayor parte de territorios de Castilla. Incluso en el siglo XVII, durante los reinados de Felipe IV y Carlos II que estudiamos en nuestra tesis de licenciatura ${ }^{2}$, sólo aparecen seis plateros aragoneses. El siglo XVIII es el que revela una afluencia superior de artífices oriundos de Aragón, que se reduce de nuevo en el siglo XIX, si bien esta particularidad puede deberse al hecho de que, al establecerse la libertad para ejercer el Arte al margen de organizaciones de carácter corporativo, son más escasas las noticias al respecto. No hemos incluido al oscense Antonio Martínez (1749-1798), de quien estamos escribiendo una extensa monografía.

Precisamos desde ahora que la documentación manejada proviene en su mayor parte del archivo de la corporación de los plateros madrileños, Congregación de San Eloy y luego Colegio Congregación, que custodia los libros de Acuerdos, de Aprobaciones, de Cuentas, de la Hermandad de Mancebos, legajos de repartos de contribuciones de distinta índole, principalmente de pago de alcabalas. Hemos añadido a cinco plateros que fueron aprendices en la Real Academia de Bellas Artes de San Fernando.

2 CRUZ VALDOVINOS, J. M., La platería y los plateros de Madrid desde 1624 hasta 1695, Tesis de licenciatura inédita, Pamplona: Universidad de Navarra, 1968. 
Las poblaciones de origen son diversas, aunque la prevalencia de Zaragoza es incontestable, pues supera la mitad de los relacionados, si bien en algunos casos hemos añadido interrogantes a esta ciudad, pues la fuente no indica el lugar de nacimiento, sino que el aprendizaje se realizó en ella. Nos hemos permitido añadir a un platero nacido en Lérida porque se indica — no sabemos si es errataque la ciudad pertenecía al obispado zaragozano y otro nacido en Cardona pero que aprendió en Zaragoza. Por orden alfabético relacionamos las localidades de origen de los plateros seguida cada una de la indicación del número de los mismos: Alcañiz (1), Ateca (1), Bardallur (1), Belchite (1), Borja (1), Calatayud (3), Daroca (1), Huesca (5), Leciñena (2), Monegrillo (1), Ojos Negros (1), Orera (1), Pino (1), Tarazona (2), Villafeliche (1) y Zaragoza (34). En total, 57 plateros, a los que se sumarán los ya mencionados de Cardona y Lérida.

Resulta muy ilustrativa la especialidad de los artífices. Los plateros de oro, 29, superan a los de plata, 22, y hay que añadir dos de filigrana, y seis más de los que no hemos podido conocer su disciplina. Podemos mencionar la marca usada por siete de los artífices que hicieron piezas de plata. Miguel de Alba, Tomás Esteban, Félix Samper - curiosamente, estos tres se aprobaron como maestros de oro-, Nazario García, Pedro Luesma, Juan Raimundo Martínez y Antonio Roserol. Podría haber marcado también Pascual Losilla, aunque, al existir varios artífices con ese apellido, no estamos seguros de que la marca le corresponda a él. La marca de Benito Gómez fue usada en Segovia y no en Madrid, como se indicará. Es posible que también marcara Pugeo, platero de oro.

Siempre que ha sido posible, se ha indicado el paso por las diferentes categorías profesionales existentes: aprendiz, mancebo u oficial y maestro. Ciertamente, no todos alcanzaron este último grado, lo que en Madrid se conseguía tras superar un examen. Algunos plateros llegaron siendo ya maestros y varios más son los que realizaron su aprendizaje en Zaragoza o en Huesca. Hemos indicado los nombres de los aprendices que tuvieron los maestros aragoneses, lo que se conoce casi exclusivamente en el siglo XVIII, gracias a que el maestro solicitaba una cédula a la corporación, aunque le contaba el tiempo transcurrido desde que lo recibió si así lo reconocía el maestro. Poseemos las relaciones del pago de la alcabala a la que estuvieron obligados los plateros madrileños desde 1747 hasta 1787 en que fueron declarados exentos de tal impuesto. También hemos recogido las cantidades satisfechas en otras ocasiones en servicios solicitados por la autoridad: adorno de la Platería en entradas reales solemnes, donativos por distintos motivos y pago del subsidio de comercio, que conocemos en 1825 y 1827. Especial importancia tiene la lista elaborada por el Colegio de San Eloy en primero de enero de 1808, donde constan, además del nombre y apellidos, lugar de nacimiento, edad, estado civil y domicilio, sobre la que elaboramos hace unos años un estudio particular ${ }^{3}$.

De algunos plateros existen trabajos monográficos que hemos aprovechado, procurando añadir noticias y recoger las principales. Son los de Javier Montalvo Martín sobre Benito Gómez ${ }^{4}$, Amelia

3 CRUZ VALDOVINOS, J.M., Plateros aprobados e incorporados al Colegio de San Eloy de Madrid (1 de enero de 1808). En: Estudios de Platería (coord. J. RIVAS CARMONA), Murcia: Cajamurcia, 2012, pp. 161-176. 
Aranda Huete sobre Andrés de la Sala ${ }^{5}$, Nuria Lázaro Milla ${ }^{6}$ y Pérez Sánchez con Camacho Cárdenas sobre Félix Samper ${ }^{7}$. Sobre los plateros del siglo XVII tratamos en nuestra tesis de licenciatura ya citada. De Alba, Asso, Calderón, Calvo, Esteban, Nazario García, Lorenzo, Luesma, Martínez, Mariano Pérez, Roserol y Villasendra hemos dado a conocer noticias y, en su caso, piezas, en varios artículos y catálogos de exposiciones. Breves noticias sobre Estella publicó María Fernanda Puerta ${ }^{8}$ y sobre García Izquierdo y Samper lo hizo Matías Fernández García ${ }^{9}$. Ha resultado sorprendente la noticia de Cadenas y Vicent sobre Yoldi ${ }^{10}$, ignorando que hubiese sido platero.

La relación de plateros que facilitamos a continuación sigue orden alfabético. Indicamos con abreviatura si fue aprobado como platero de oro, de plata o de filigrana. El lugar de nacimiento y las fechas de nacimiento y muerte, y si no fueran conocidas, la fecha más tardía en que se tiene noticias, y en bastantes ocasiones aquéllas en que aparece documentado. Todas las fechas citadas llevan el mes en número, a fin de abreviar el texto. Por lo mismo, hemos suprimido las notas a pie de página que correspondían a las fuentes de la noticia en la corporación de plateros madrileños. Según las fechas, pertenecen a Libros de aprobaciones (1724-1814), Libro de la Hermandad de Mancebos (1590-1778), Libro de Aprendices (1779-1879), Libro de Acuerdos (1797-1827 y 1827-1872), Legajo de alcabalas (indicamos en reales las cantidades asignadas), Legajo 64 (certificaciones de aquellos no naturales de Madrid), Legajo 80, relaciones varias de donativos y repartimientos en ocasiones concretas.

Nos ha parecido oportuno incluir una relación de los plateros que están documentados en Zaragoza y que aparecen citados en las fichas que incluimos. Las noticias sobre casi todos ellos pueden encontrarse en la obra de Juan Francisco Esteban Lorente ${ }^{11}$. Además añadimos a dos maestros en Huesca, José Estrada y Nicolás Julián, todavía no suficientemente estudiados ${ }^{12}$. No hemos añadido otras que poseemos sobre piezas de Albéniz, Bestenobi, Dargallo, Estrada, Noble, Sanasi y del contraste Xea, pues no era el propósito de este artículo.

\section{ALBA, Miguel de (o). Orera (Zaragoza). 1745-1790.}

Ingresó en la Academia de San Fernando en $1770^{13}$. Había aprendido en Zaragoza. Su solicitud de aprobación pasó a los aprobadores el 25-9-1772, hizo el examen el 26-10-1772 y recibió la aprobación

5 ARANDA HUETE, A., La joyería en la Corte durante el reinado de Felipe Ve Isabel de Farnesio. Madrid: Fundación Universitaria Española, 1999, pp. 314-316.

6 LÁZARO MiLlA, N., Félix Samper. Historia de un diamantista, Madrid: Museo del Romanticismo, 2013.

7 PÉREZ SÁNCHEZ, M. y CAMACHO CÁRDENAS, E.M., Consideración social y proyección internacional de un diamantista español: Félix Samper Fuentes (1810-1877), de Madrid a París y Londres. En Estudios de Platería (coords. J. RIVAS CARMONA e I.J. GARCÍA ZAPATA), Murcia: Universidad de Murcia, 2019, pp. 431-445.

8 PUERTA ROSELL, M ${ }^{\mathrm{a}}$ F., Platería madrileña. Colecciones de la segunda mitad del siglo XVII, Madrid: Fundación Universitaria Española, 2005, pp. 250-251 y 303.

9 FERNÁNDEZ GARCÍA, M., Parroquias madrileñas de San Martín y San Pedro el Real. Algunos personajes de su archivo, Madrid: Caparrós, 2004, p. 420.

10 CADENAS Y VICENT, V., Caballeros de la orden de Santiago. Siglo XVIII, Madrid: Hidalguía, 1979, nº 1384.

11 ESTEBAN LORENTE, J.F., La platería de Zaragoza en los siglos XVII y XVIII, 3 vols., Madrid: Ministerio de Cultura, Dirección General de Patrimonio Artístico, Archivos y Bibliotecas, Centro Nacional de Información Artística, Arqueológica y Etnológica, 1981.

12 ARCO, R. del, Orfebres oscenses (siglos XVI, XVII y XVIII). Revista de la Academia de Buenas Letras. 1912, no 47 , pp. 375 y 377.

13 PARDO CANALÍS, E., Los registros de matrícula de la Academia de San Fernando de 1752 a 1815, Madrid: CSIC, 1962. 
el 26-11-1772. Vivió en la calle del Carmen 8, $2^{\circ}$ con tienda (manzana 376). Recibió como aprendiz a José Tirado, natural de Borja, el 23-7-1779, contándole el tiempo desde 1-10-1778. Satisfizo bajas cantidades de alcabalas:1765-1773, 12; 1774-1775, 14; 1776-1778, 16; 1779-1780, 4; 1781-1782, 4; 1783-1784, 4; 1785-1786, 4; 1787, 2. En 1783 contribuyó con 4 reales al donativo solicitado por el Rey. En la relación de plateros de Madrid de 1786 figura como jornalero. En 1790 el Colegio entregó una limosna para su entierro.

Conocemos un salero de 1782 con su marca: AL/BA (col. Hernández Mora Zapata) ${ }^{14}$. Dada su situación y que estuviera aprobado en la facultad de oro, cabe sospechar que cediera su marca a un platero no aprobado, hecho poco frecuente pero no excepcional.

\section{ALBERO, Antonio (o). Leciñena (Zaragoza). 1716/1717-1782.}

Según las certificaciones presentadas al pedir la aprobación como maestro, estuvo seis años de aprendiz con Juan Rosell, dos años de mancebo con Bernardo Espinar, probablemente mal escrito por Espinós, en Zaragoza y ocho años en Madrid. Pasó a practicar y el examen se realizó el 30-31749; en él hizo varios dibujos y recibió la aprobación el 29-8-1749. Satisfizo importantes cantidades por la alcabala: 1747-1748, 12; 1750-1752, 45; 1753-1759, 175; 1760-1764, 250; 1765-1773, 450; 1774-1775, 100; 1776-1778, 166; 1779-1780, 120; y luego a nombre de su viuda, 1781-1782, 100; $1783-1784,40 ; 1785-1786,50 ; 1787,20$, lo que muestra todavía un obrador activo. Para el gasto de la entrada solemne de Carlos III contribuyó en 1760 con 180 reales para el adorno de la Platería, solo superado por 16 plateros entre 320 contribuyentes. Ocupó varios oficios en la Congregación de San Eloy: aprobador (1750-1752, 1764-1765, 1768-1769, 1773-1774), tesorero de propios (1752-1757), y mayordomo (1763). Además se le encargó en 1763 que gestionara, junto con Ángel Gonzalo, Juan de San Faurí y Manuel Castilla, la hechura de una efigie de San Eloy que realizó Juan Pascual de Mena en 1764 y que se conserva en la iglesia de San José de Madrid, y en 1773 que informara, con Antonio de Lara, sobre la solicitud de Bartolomé de Fuentes para ser nombrado tasador. El 15 de julio de 1765 actuó como tasador de joyas por parte de doña Mariana Sáez, identificándose como platero de oro de los Reyes y de 49 años de edad ${ }^{15}$.

Tuvo numerosos aprendices y oficiales en su obrador y muchos de ellos llegaron a recibir aprobación como maestros: Joaquín Ripando, de Pamplona (18-7-1758), Antonio Sandoval, de Zaragoza, que estuvo once años con él a partir de 28-9-1764, Francisco Gómez de Velasco, de Mansilla de la Sierra (28-9-1764), Juan Serrano, de Madrid (18-12-1770) hijo del tasador José, Francisco Javier Martínez Joya, de Mansilla e la Sierra (31-5-1771) y Pedro Marcén, de Madrid, seguramente su sobrino (2-6-1792). Otros aprendices no llegaron a obtener la aprobación como maestros, pero conocemos las fechas en que solicitó a la Congregación la cédula de aprendizaje: Miguel Albero Bagués, de Zaragoza, hijo de José y de Jorja, seguramente pariente suyo (26-11-1767), Francisco Javier Gregorio Bolaños (29-8-1769), Dámaso Abad, de Burgo de Osma, que estaba con Francisco Montero desde

14 CRUZ VAldovinos, J.M., El arte de la plata. Colección Hernández-Mora Zapata, Murcia: Fundación Cajamurcia. 2006, nº 112.

15 ARANDA HUETE, A., La joyería en la Corte durante el reinado de Felipe V e Isabel de Farnesio, Tesis Doctoral, Madrid: Universidad Complutense, 1996, p. 382. 
1769 y que consintió en que pasase con Albero (18-12-1772), Francisco Juan Mariano, de Zaragoza (30-7-1773) y Vicente Antonio Martínez de Madrid (18-5-1781, contándole el tiempo desde 24-41781). Vivió en la Platería 12, 2º (manzana 417). Murió entre el 1 de enero y el 1 de mayo de 1782.

\section{ASSO, Mauricio Julián (o). Zaragoza. 1751-1808/1814.}

Quizá hijo de Pedro, maestro en Zaragoza en 1723, casado, todavía sin hijos y documentado hasta 1755. Ingresó en la Hermandad de Mancebos plateros de Madrid en 1776. Recibió la aprobación el 26-5-1786. Satisfizo en dos ocasiones la alcabala: 1785-1786, 4; 1787, 2. Figura en la relación de 1-1-1808 casado y viviendo en la calle de la Magdalena, 4, pero no aparece en la correspondiente a la oferta mensual al Rey de 1815.

\section{AVIZANDA, Tomás de (o). Daroca (Zaragoza). 1725/1735-1781.}

En 1757 presentó ante la Congregación de San Eloy una certificación firmada y sellada por el Colegio de plateros de Zaragoza de haber cumplido los años de aprendiz y de mancebo. El 24-5-1757 pasó a practicar y el 7-6-1757 recibió la aprobación como maestro. Declaró que vio a Pedro Luesma trabajar en Zaragoza cuando éste pidió la aprobación en Madrid en 1757. Satisfizo las siguientes cantidades por la alcabala: 1753-1759, 30; 1760-1764, 100; 1765-1773, 135; 1774-1775, 50; 1776-1778, 50; 1779-1780, 70; 1781-1782, 16. Para el gasto de la entrada solemne de Carlos III y María Amalia contribuyó en 1760 con 15 reales, una baja cantidad. Tenía casa y tienda en la calle de los Bordadores 15 (manzana 388). Murió entre el 1 de enero de 1781 y el 1 de mayo de 1782. Es probable que Segundo de Avizanda, aprendiz de platero de plata con Manuel Antonio Rodríguez desde 21-11-1770 y que pasó con Martín Benítez Pulido el 30-7-1773 fuera pariente suyo.

\section{BENITO GÓMEZ, Juan de la Cruz (p). Tarazona (Zaragoza). 1733-1810.}

Puesto que recientemente, el doctor Francisco Javier Montalvo Martín ha dedicado un artículo monográfico a este platero $^{16}$, nos limitamos a señalar aquí los datos de su paso por Madrid procedentes del Colegio Congregación de San Eloy.

Fue convocado a examen el 9-3-1779 y recibió la aprobación como maestro platero de plata el 15-3-1779 tras hacer un espadín. Se indica que era natural de Tarazona y vecino de Segovia. Se le examinó - como a Bernardo Corral — por orden de la Real Junta General de Comercio y Moneda y por su mandato, "como van a continuar en Segovia no se les hicieron las prevenciones usuales", esto es, no se les cobró lo acostumbrado.

\section{CALDERÓN, José (o). Ateca (Zaragoza). 1753-1815.}

El 28-2-1772 Nicolás Miguel Fernández de Moratín solicitó su cédula de aprendizaje y en 1776 ingresó en la Hermandad de Mancebos plateros de San Eloy. Tardó muchos años en solicitar la aprobación como maestro, que recibió el 26-2-1799, por lo que pensamos que actuó como oficial del propio Fernández de Moratín. Ambos figuran en la relación de maestros plateros de Madrid formada

16 MONTALVO MARTÍN, F.J., ref. 4., pp. 397-408. Da a conocer una quincena de piezas, amplia documentación sobre sus labores y la marca usada: BE/NITO. 
el 1 de enero de $1808^{17}$. Calderón estaba casado y vivía en la calle de la Comadre, 18. En el donativo de 1815 por las urgencias del Reino figura con 20 reales, cantidad baja.

\section{CALVO, Juan José (p). Huesca. 1762-post 1815.}

El 30-7-1773, Pedro Sáez, que era platero de oro, solicitó cédula de aprendizaje para un Juan Calvo, que puede ser este platero. El 21-2-1785 fue reconocido como mancebo y se indica que había aprendido en Huesca con José Estrada. Recibió la aprobación el 9-2-1787 y ese año pagó 6 reales por la alcabala. Figura en la relación de plateros de 1-1-1808, casado y viviendo en la calle del León, $22^{18}$. En el donativo de 1793 para la entrada solemne en Madrid de Carlos IV figura con 6 reales y en el de 1815 por las urgencias del Reino contribuyó con 40 reales.

\section{CASTRO DE GISTAU, Roque (o). Zaragoza. Doc. 1774-1793.}

Cuando solicitó examinarse como maestro en la Congregación en San Eloy certificó que había aprendido en Zaragoza. El 22-11-1774 dibujó un collar con su herradura, flores, cintas, lazos y dos almendras, una pendiente del lazo y la otra de la herradura con su arracada correspondiente. Recibió la aprobación el 19-12-1774. Las cantidades pagadas por la alcabala fueron: 1774-1775, 50; 1776-1778, $75 ; 1779-1780,8 ; 1781-1782,8 ; 1783-1784,20 ; 1785-1786,12 ; 1787,6$. El descenso apreciable en el impuesto justifica que en una relación de 1786 se haga constar que era jornalero. Sin embargo, figuró en la oferta mensual al Rey de 1793 con 40 reales, en quinto lugar entre 230 plateros contribuyentes. Tuvo un aprendiz en los primeros años, el madrileño Manuel Mesones (1-2-1776), y posteriormente dio de alta a sus cuatro hijos madrileños: Salvador Teodoro (27-2-1784, contando desde el 24 de enero anterior), Plácido (5-1-1788), Juan Bautista y Mariano (24-10-1790, contando el primero desde 256-1788 y el segundo desde 17-8-1790). Ninguno de los cinco consta que llegara a ser siquiera oficial. Vivió en la calle Mayor 7, $3^{\circ}$ (manzana 388 ).

\section{DUQUE, Gabriel (o). Monegrillo (Zaragoza). +1779.}

Solicitó la aprobación como maestro el 29-1-1771 y la recibió el 27-2-1771. Certificó que había aprendido en Zaragoza donde había recibido también la aprobación. Además, había estado más de diez años en Madrid trabajando en el obrador de Francisco Sáez y de Manuel López Sáez, plateros reales; en efecto, en el reparto para el gasto del adorno de la Platería con motivo de la entrada solemne de Carlos III y María Amalia en 1760, figura con 20 reales entre los mancebos. En el examen dibujó un ramo para el pecho de diferentes flores, hojas y troncos, con unas cintas. De manera sorprendente, figura en el pago de la alcabala para el septenio 1753-1759 con 30 reales, quizá por su trabajo como aprobado en Zaragoza; después figura con cifras bajas porque consta que trabajaba a jornal: 17651773, 30; 1774-1775, 22; 1776-1778, 8. Vivía en la calle de la Concepción Jerónima 7, 2º (manzana 160). Había muerto ya el 22-5-1779.

17 CRUZ VALDOVINOS, J.M., ref. 3, pp.164 y 166.

18 CRUZ VALDOVINOS, J.M., ref. 3, p.165. 


\section{ESTEBAN, Tomás (o). Ojos Negros (Teruel). 1765-1809.}

Aprendió con su tío Antonio Abad, que obtuvo su cédula de aprendizaje el 11-8-1779 pero corriendo el tiempo desde 17-5-1777. Recibió la aprobación como maestro el 3-12-1786. Pagó la alcabala el último año en que lo hicieron los plateros, 1787, con 16 reales. En la oferta mensual al rey en 1793 figura con 12 reales, cantidad media. Aparece en la contribución exigida por José Bonaparte en 1809 con 2.934 reales en el tercer y último tramo de los plateros y agregados, pero el reparto hecho por el Colegio en abril se hace a su viuda. Sólo se registra que recibiera un aprendiz, Juan Antonio Sánchez, el 24-3-1787. En la relación de 1-1-1808 figura viviendo en la calle del Carmen. Aunque recibió la aprobación como maestro platero de oro, facultad de su tío, se conoce su marca en piezas de plata: $\mathrm{T}$. /ESTE/VAN ${ }^{19}$.

\section{ESTELLA, Diego (o). Huesca. + 1688.}

Vecino de Madrid desde 1646. Ingresó en la Hermandad de Mancebos plateros en fecha desconocida. Fue aprobado como maestro platero de oro el 4-3-1660; dibujó e hizo una sortija de 21 diamantes. Entró en la Congregación de San Eloy el 3-7-1661. Ocupó los siguientes oficios: mayordomo (1664), diputado (1665), aprobador (1670-1672). Casó con Francisca Manuela Simón; su nieto Matías Knoler fue ensayador de la Casa de la Moneda. Murió en julio de 1668. En su inventario se anotan 37 piezas de plata por un por un valor de 15.560 y $1 / 2$ reales $^{20}$.

\section{ESTRADA, Pedro Tomás (p). Zaragoza. Doc. 1779.}

Hijo del famoso platero zaragozano Domingo Estrada. Ingresó en la Hermandad de Mancebos plateros de San Eloy el 1-5-1779. No hay más noticias suyas en Madrid y es posible que regresara a su ciudad natal.

\section{FERRER, Tomás (p). Zaragoza. Doc. 1757.}

Solicitó la aprobación como maestro platero de plata el 30-9-1757, después de haber aprendido en Zaragoza con Diego Dieste y fue aprobado el 31-10-1757.

No vuelve a aparecer en la documentación madrileña y puede ser que regresara a la ciudad aragonesa. En la relación de los plateros que contribuyeron al adorno de la Platería en 1760 con motivo de la entrada solemne de Carlos III y María Amalia figura su nombre, pero con cero reales.

\section{GALICIA, Hilario (p). Calatayud. (Zaragoza). Doc. 1823.}

En la reunión de la junta particular del Colegio de San Eloy de 29-12-1823 se vio su petición de aprobación e incorporación como maestro. Pero sólo presentó una carta, por lo que se le indicó lo que tenía que hacer para elevar correctamente la solicitud. No consta que reiterara su petición.

19 CRUZ VALDOVINOS, J.M., ref. 3, p.166. Las piezas que conocemos son una esponjera de 1805 (Subastas Segre, Madrid, 24-X2012, lote 410) y una mancerina de 1808 (comercio madrileño).

20 PUERTA ROSELL, Ma F., ref. 8, pp.250-251 y 303. 


\section{GARCÍA, Manuel. Zaragoza. 1767-post. 1808.}

En la relación de los oficiales existentes en 1 de enero de 1808 en Madrid conservada en el Colegio Congregación de San Eloy, figura este platero, con la ciudad de origen y edad, casado y viviendo en la calle de Santa María, 22. No aparece entre los que cotizaron en la oferta mensual al rey de 1815.

\section{GARCÍA, Nazario (p). Zaragoza. 1810/1815-post 1862.}

El 2-7-1839 presentó certificación de Rudesindo Xea, contraste y platero de Zaragoza, de que había estado seis años de aprendiz y diez de mancebo y que era hijo de platero zaragozano. Solicitó aprobación e incorporación al Colegio de San Eloy el 30-7-1839 y se le concedió el 29-11-1839. En 1862 se anunciaba en el "Anuario General de Comercio" entre las platerías en la calle de las Carretas, 11, pero no figura en 1863. Empleó la marca: N/GARCIA con marco mixtilíneo de siete lados ${ }^{21}$.

\section{GARCÍA IZQUIERDO, Julián (o). Pino (Zaragoza). Doc. 1857.}

Hijo de Aquilino y de Francisca, casó en la parroquia de San Pedro de Madrid el 14-5-1857 con Julia Romana, de Madrid, hija de Joaquín y Antonia de España. Vivían en la Cava Baja 45 y $47^{22}$. Figura como diamantista, pero no aparece en la documentación del Colegio de San Eloy. Su lugar de nacimiento podría ser Pina, ahora Pina de Ebro.

\section{GARISA, Manuel Domingo (fil). Zaragoza. Doc. 1779.}

El 26-7-1779 ingresó en la Hermandad de Mancebos plateros; declaró Pedro de Losa que había aprendido con él durante seis años. No consta su aprobación.

\section{GARRO, Bernardo (o). Zaragoza. h. 1690-post 1755.}

El 24-6-1718 ingresó en la Hermandad de Mancebos plateros. La coincidencia de nombre y apellido nos lleva a pensar que regresó pronto a Zaragoza y que sea el mismo que fue oficial de José Godó y luego aprobado como maestro en Zaragoza en 1720. Godó había casado, antes de 1709, con Joaquina Portel, viuda del platero Baltasar Garro y madre de Bernardo, su último hijo con Baltasar. La documentación de Bernardo en Zaragoza llega hasta $1755^{23}$.

\section{GIL, Joaquín (o). Bardallur (Zaragoza). 1738-post 1827.}

Fue bautizado como José Joaquín Gil Burriel, hijo de Pedro, de Bardallur, y de María, de Zaragoza. E1 25-5-1773 pidió la aprobación en Madrid. Se le mandó que presentara la documentación correspondiente. El 3-7-1773, en Zaragoza, el mayordomo menor de la corporación de plateros Clemente Moliner y los colegiales Raimundo Noble y Manuel Soler certificaron con la firma del secretario

21 CRUZ VALDOVINOS, J.M., Relación de plateros activos en Madrid en 1861. En: Estudios de Platería (coord. J. RIVAS CARMONA), Murcia: Universidad de Murcia, 2013,p.166. Conocemos las siguientes piezas: cafeteras (1842), jarro (1849), velón (1853) en colecciones privadas, cáliz (1844) en el Seminario de Ciudad Real, candeleros de 1845 (Terra Sancta Museum, Jerusalén) y candeleros (1859) en el convento de las Angélicas de Cuenca.

22 FERNÁNDEZ GARCÍA, M., ref. 9, p.420.

23 ESTEBAN LORENTE, J.F., ref. 11, vol. I: pp.119-120 y 123-124. 
Bernardo Lorda, que Joaquín estuvo tres años como aprendiz con Miguel Arragueta, otros tres con Bernardo Espinós y unos días con Juan Leredo. El 6-7-1773 declararon como testigos en Madrid los plateros zaragozanos Francisco Pascual de Villasendra: que se crió con Gil y que sus padres y abuelos fueron labradores y Fernando López: que lo conocía desde los ocho años porque fue aprendiz del hermano de su mujer, Juan José Pugeo, y que aprendieron en la misma casa; Francisco Suñer también declaró que le conocía. El 30-8-1773 pasaba a practicar e hizo "el dibujo de una piocha de hojas y flores y plumas y de una sortija que sacó de fuego y la engastó con un diamante color de rosa en el medio de dos orlas, una de esmeraldas y otra de diamantes, brazo abierto, chapa lisa de oro". Recibió la aprobación como maestro el 28-9-1773.

Se le repartieron unas cantidades medianas correspondientes a la alcabala: 1765-1773, 30; 17741775, 38; 1776-1778, 70; 1779-1780, 40; 1781-1782, 40; 1783-1784, 25; 1785-1786, 60; 1787, 30. En 1783 contribuyó con 30 reales al donativo solicitado por el Rey y en 1793 con 15 reales en la oferte mensual a Carlos IV. En 1815 figura con 100 reales, elevada cantidad, como aportación por las urgencias del Reino. En los subsidios de Comercio de 1825 y 1827 figura con 55 y 80 reales respectivamente.

Quizá fue su hijo Joaquín Gil, que entró de aprendiz con Antonio Magro, platero de plata, el 25-91793, contándole el tiempo desde 15-7-1793. El maestro Joaquín Gil vivió y tuvo obrador en la calle del Carmen 5, $3^{\circ}$ (manzana 377).

\section{GIL, Sebastián (o). Villafeliche (Zaragoza). 1770-post 1808.}

Sobrino de Joaquín, entró como aprendiz suyo el 22-10-1785, contándole el tiempo desde 1-101783. En la relación de 1-1-1808 figura como oficial, soltero, viviendo en la calle de los Milaneses, 33.

\section{GOSA, Pedro (fil). Zaragoza. Doc. 1755-+1785/1786.}

Aprendió en Zaragoza con Pedro de Asso. Pasó a practicar el 16-6-1755 y recibió la aprobación en Madrid el 29-8-1755 después de hacer un relicario de filigrana. Se le repartieron cantidades bajas, seguramente porque la labor de filigrana no dejaba mucha ganancia, para el pago de la alcabala: 17531759:40; 1760-1764: 60; 1765-1773: 270; 1774-1775: 44; 1776-1778: 26; 1779-1780: 20; 17811782: 10; 1783-1784: 10. El 28-2-1765 solicitó licencia para recibir a trabajar en su casa a Manuel Gorriz que había aprendido en Pamplona y se le respondió que podría recibirle cuando las informaciones estuvieran autorizadas; no volvió a haber noticias ${ }^{24}$. Fue maestro de Juan Antonio Herreros, de Madrid, que pasó a examinarse como maestro el 31-5-1771 y, tras realizar “jarrillas" para escribanía, recibió la aprobación como maestro platero de plata el 18-6-1771. El 27-8-1772 solicitó cédula para su aprendiz Bartolomé Gasco, de Colmenar Viejo, que ingresó en la Hermandad de Mancebos en 1776 y fue aprobado el 2-7-1795 como platero de filigrana. El 18-4-1776 recibió la cédula de aprendizaje de Calixto Ortega. Fue también maestro de Manuel Domingo Garisa, de Zaragoza, y declaró que había estado con él durante seis años; ingresó en la Hermandad de Mancebos el 27-7-1779. Vivió en la Plaza Mayor 26, $2^{\circ}$ (manzana168) y tuvo tienda en la calle de los Esparteros, 3(manzana 201). En 1786 ya había muerto.

24 No llegó a aprobarse en Pamplona. Casó con Fermina Espetillo Larumbe, hija y hermana de plateros: ORBE SIVATTE, M., Platería en el taller de Pamplona en los siglos del Barroco, Pamplona: Gobierno de Navarra, 1999, p.124. 


\section{GREGORIO, Calixto Antonio (p). Huesca. Doc. 1779.}

Ingresó en la Hermandad de Mancebos plateros de Madrid el 7-12-1779, certificando que había sido aprendiz de José Estrada en Huesca. No consta su aprobación en Madrid²5.

\section{JAL, Pedro de (p). Zaragoza. Doc. h. 1753-1760.}

Solicitó la aprobación como maestro y el 21-10-1757 pasó a practicar haciendo un salero a la inglesa; fue aprobado el 29-11-1757. Había aprendido en Madrid con Jean Henri Arnal y, tras su muerte, completó el tiempo que le faltaba con Jean Thomas Larreur; ambos maestros fueron plateros reales. Tuvo como aprendiz a Manuel Rodríguez, que recibió la aprobación como maestro el 31-81767. Solo figura en las listas de pago de la alcabala por el septenio 1753-1759, y pagó 60 reales. Todavía en 1760 figura entre los plateros contribuyentes al gasto de adorno de la Platería con motivo de la entrada de Carlos III y María Amalia, con 80 reales, cantidad de alguna importancia. No existen datos posteriores, por lo que hay que pensar que falleció o abandonó la corte en 1760 o poco después.

\section{LAVEDAN, Joaquín (p). Huesca. Doc. 1778-1779.}

Pedro Luesma solicitó para él la cédula de aprendizaje el 4-8-1778, el 1-2-1779 y el 23-7-1779, en que se le concedió, corriéndole el tiempo desde 7-10-1778. Las sucesivas negativas pudieron deberse a la ausencia de certificados de bautismo. No consta que llegara a mancebo ni a maestro en Madrid.

\section{LÓPEZ, Benito (o). ¿Zaragoza? Doc. 1768-1778.}

El 30-1-1768 y el 29-2-1768 solicitó la aprobación justificando que había aprendido con Bernardo Garro en Zaragoza, que se le denegó porque pretendió tomar tienda y habitación fuera de la demarcación de la Platería, lo que era contrario a ordenanzas. El 10-7-1768 explicó que tenía casa en la Puerta de Guadalajara, y entonces se le admitió a examen, en que dibujó una pieza de garganta, arracada, brocha y piocha. Recibió la aprobación el 18-7-1768. Los pagos por alcabala fueron relativamente elevados: 1765-1773, 300 y 1774-1775,112. El 10-12-1778 se le menciona como ausente de la Corte y no figura en el reparto de la alcabala por el trienio 1776-1778.

\section{LÓPEZ, Fernando (p). Zaragoza. Antes de 1744-+1787.}

Aprendió en su ciudad natal; presentó en Madrid el título de colegial de Zaragoza de 10-7-1744 que le habilitaba para ejercer el Arte, donde figuraban como mayordomos Valero Agramón y Sebastián de Arque; iba acompañado de la certificación de 24-7-1763 firmada por Juan Rosell como secretario, Antonio Dargallo como mayordomo mayor y Pedro de Fuentes como mayordomo compañero. Sin embargo de su título solicitó la aprobación como maestro en Madrid y pasó a practicar el 20-5-1765, recibiendo la aprobación el 14-6-1765. El 6-7-1773 declaró como testigo en relación con Joaquín Gil y manifestó que le había conocido desde los ocho años porque fue aprendiz con el hermano de su mujer, Lorenza Artal. Vivía entonces en la casa de las Conchas, en la bajada del convento de los Ángeles.

25 En el Museo de Huesca se conserva una fuente con inscripción de la cofradía de Nuestra Señora de la Piedad de la Universidad y datada en 1796, con marcas de Huesca y de GREGORIO que se adjudica a Pablo Gregorio; si es así sería pariente de Calixto. Cfr. CERES. En Burbáguena (Teruel) hay unas vinajeras y una palmatoria con la misma marca de artífice pero con las de Zaragoza, que fechamos en 1830/1840. 
Sus pagos por la alcabala no son elevados: 1765-1773, 60; 1774-1775, 14; 1776-1778, 10; 17791780,$6 ; 1781-1782$, 6; 1783-1784, 6; 1785-1786, 4; en 1787 se le asignaron 2 reales, que fueron satisfechos por su viuda. En 1783 no figura entre los contribuyentes al donativo del rey.

Tuvo casa y obrador en la calle de los Tintes a los Caños del Peral, 21, principal (manzana 418). Recibió como aprendiz a su hijo Juan Pablo, que obtuvo la cédula el 6-11-1776, contándole el tiempo desde 24-6-1773; ingresó en la Hermandad de Mancebos en 1779 con certificación de su padre; fue aprobado como maestro el 29-9-1785; pagó alcabala por separado de su padre y de su madre: 17851786, 10 y 1787, 8. Probablemente dirigía ya el obrador de su padre desde el comienzo. A su vez, tuvo como aprendiz a su hijo Manuel a partir de 30-9-1800, contándole el tiempo desde 1-10-1800.

\section{LORENZO, Mariano Tomás (o). Zaragoza. 1762-post 1815.}

Fue aprendiz el 2-5-1776 con Juan de Bastos que dio su beneplácito para que pasara luego con Antonio Martín. Recibió la aprobación como maestro el 22-5-1798. En la relación de 1-1-1808 figura casado, viviendo en la calle Mayor, 5. En el donativo por las urgencias del Reino de 1815 figura con 20 reales.

\section{LOSILLA, Pascual (p). Calatayud (Zaragoza). 1777/1778-post 1795.}

Ingresó en la Real Academia de Bellas Artes de San Fernando el 2-3-1795. Es posible que fuera hijo de Miguel, nacido en 1730 y que figura como mancebo en Zaragoza en 1762 y como platero, quizá maestro, en 1774. También puede ser pariente de Judas Losilla, nacido en 1802 en Calatayud, documentado en Almazán (Soria) en 1839-184126. Es frecuente hallar piezas con la marca LOSILLA en Calatayud y poblaciones de las provincias de Zaragoza, Navarra y Guadalajara datadas entre 1847 y $1861^{27}$, que parece que sólo pueden corresponder al último citado.

\section{LUESMA, Pedro (p). Zaragoza. H. 1730-1790/1807.}

En 1757, Manuel Roses, secretario del Colegio de plateros de Zaragoza, certificó que Ana María Pasaña, viuda de Antonio Bestenovi, declaró que Luesma estuvo seis años de aprendiz y algún tiempo de mancebo con su marido. En 1765, Julián del Campo Montemayor certificó que lo tuvo como mancebo y lo mismo hizo Miguel Antonio Lizasoaín y Tomás de Avizanda declaró que vio a Luesma en Zaragoza y también en Madrid con Yves Larreur y con Juan de Coma Juncosa. El 20-5-1765 pasó a practicar el examen e hizo diferentes dibujos; el 14-6-1765 recibió la aprobación como maestro platero de plata en Madrid. El 21-11-1770 solicitó que se le diera tienda y casa dentro de la demarcación, pero la Congregación contestó que no había lugar, pues no era de su competencia.

En los pagos de alcabala sorprende que se le repartiera desde doce años antes de que obtuviera la aprobación, lo que es excepcional y cabría pensar que tenía ingresos trabajando como oficial. Las cantidades, muy elevadas en la última etapa, fueron: 1753-1769, 40; 1760-1764, 30; 1765-1773, 180; 1774-1775, 56; 1776-1778, 116; 1779-1780, 150; 1781-1782, 200; 1783-1784, 180; 1785-1786, 299;

26 HERRERO GÓMEZ, J. y MÁRQUEZ MUÑOZ, J.Á., La platería en Almazán, Soria: Ayuntamiento, 1994, p. 34.

27 ESTEBAN LÓPEZ, N., Orfebrería de Sigüenza y Atienza, Tesis doctoral inédita. Madrid: Universidad Complutense de Madrid, 1992, p. 62. 
1787, 120. En 1783 contribuyó con sólo 4 reales al donativo solicitado por Carlos III y en 1793 en la oferta mensual a Carlos IV con 20 reales, ocupando el puesto 18 entre 230 plateros.

Tuvo los siguientes aprendices: Juan Raimundo Martínez que obtuvo cédula de aprendizaje el 28-1-1772, ingresó en la Hermandad de Mancebos el 24-6-1777 y fue aprobado como maestro el 265-1783; Antonio de la Oliva, de Madrid tuvo cédula de aprendizaje el 1-2-1775; Joaquín Lavedán, de Huesca, de quien nos ocupamos en este trabajo; Juan Agustín Gamón, de Piña de Campos (Palencia): cédula de 10-4-1783, contándole desde 26-6-1782 y Francisco García, cédula de 27-11-1789, contándole desde 2-11-1789.

Vivía y tenía su tienda en la calle de Fuencarral 7 (manzana 302). Utilizó la marca LV/ES/MA. Conocemos varias piezas: bacía de 1770 (col. privada), tres soperas de 1774 (comercio de París), cubiertos (colección privada) y paleta de postre (M. A. N) de 1783; juego de aguamanil sin marcas cronológicas (col. privada) (Fig. 1). En 1781 y 1785 trabajó para los duques de Osuna, haciendo entre otras piezas una vajilla que costó medio millón de reales ${ }^{28}$.

\section{MARCÉN Y ALBERO, José (o). Leciñena (Zaragoza). +1794/1807.}

Cuñado de Antonio Albero, aprendió en Madrid con el valenciano José Dueñas y Briones. Pasó a practicar el 21-3-1755 e hizo varios dibujos. Recibió la aprobación como maestro el 28-5-1755. Pagó las siguientes cantidades por la alcabala: 1753-1759, 50; 1760-1764, 50; 1765-1773, 72; 1774-1775, 20; 1776-1778, 40; 1779-1780, 34;1781-1782, 34; 1783-1784, 50; 1785-1786, 60; 1787, 30. En 1760 contribuyó con 20 reales al gasto para la entrada solemne de Carlos III y María Amalia, en 1783 con 30 reales al donativo solicitado por el Rey y en 1793 con 15 reales en la oferta mensual a Carlos IV.

Tuvo los siguientes aprendices: Quintín Gasco que obtuvo cédula el 29-2-1768; su hijo Antonio Marcén la obtuvo el 24-9-1783, contando desde 1 de enero de ese año; Camilo Alarcón el 28-5-1790 contando desde 19-4-1790, y fue aprobado como maestro el 27-3-1804; Pedro Marcén, seguramente su hermano, aprendió con Antonio Albero. En 1761 tenía obrador en la calle de los Coloreros. Vivió con su cuñado Albero en la Platería 12, $2^{\circ}$ y también en el 5, $2^{\circ}$ (manzana 417). Casó con Manuela Gamboa, que le sobrevivió.

\section{MARTÍNEZ, Juan Raimundo (p). Calatayud (Zaragoza). 1761-1808/1815.}

Aprendió con Pedro Luesma, que pidió cédula el 28-1-1772; ingresó en la Hermandad de Mancebos el 24-6-1777. Recibió la aprobación el 26-5-1783. El mismo año contribuyó con 12 reales al donativo solicitado por el Rey. Satisfizo pequeñas cantidades por la alcabala: 1783-1784, 16; 17851786, 24; 1787, 12. En 1793 figura con 15 reales en la lista de la oferta mensual a Carlos IV. 
Tuvo los siguientes aprendices: Francisco Ramón Roger, de Madrid, el 17-11-1783 contando desde 30-9-1783, pero el 6-7-1784 consta que le despidió; Cipriano Tomás Gómez, para el que pidió cédula el 11-8-1785 y fue aprobado como maestro el 27-11-1794; Miguel Cabañas, el 27-10-1794 contando desde 2-7-1794; y su hijo Pablo, con cédula del 20-12-1796 contando desde 1-12-1796.

En la relación de 1-1-1808 aparece casado, viviendo en la calle de los Yeseros, 7, pero ya no está en la lista del donativo de 1815. Pensamos que le corresponde la marca MAZ con trazo curvo sobre las letras, que hemos visto en algunas piezas en subastas madrileñas.

\section{MENTEGUíA, Juan Francisco de (o). Zaragoza. Doc. h. 1725-post 1778.}

Aprendió en Madrid con Francisco de Párraga, que murió en 1729. Es posible que fuera hijo del platero zaragozano Francisco Menteguía, aprobado en 1695 y hermano de Francisco, aprobado en 1731 en Zaragoza, ambos plateros de oro. Juan Francisco recibió la aprobación el 26-11-1740. El 17-10-1745 figura entre los cuatro pretendientes a portero de la Congregación de San Eloy y resultó elegido el 20-11-1745. En 1752 y 1753 se le concedieron sendos auxilios de 100 ducados cada uno. En 1759 reclamó que le debían parte del sueldo y le fue abonado. El 19-12-1760 recibió una gratificación de 200 reales por el mucho trabajo que tenía. No figura entre los contribuyentes al gasto para el adorno de la Platería en 1760 con motivo de la entrada solemne de Carlos III y María Amalia. Aparece como pobre de lista el 10-12-1778.

\section{MONCLÚS, José (p). Zaragoza. Doc. 1656-1661.}

Figura desde 1656 como vecino de Madrid. Fue aprobado como maestro platero de plata el 26-11661; dibujó e hizo un jarro, que entonces sería de pico. No figura en la relación de contribuyentes al donativo de 1694.

\section{MOLINER, Francisco (o). Zaragoza. 1762-1787.}

Seguramente era hijo de Francisco, cuya tienda en Zaragoza fue visitada en 1755. Larruga indica que fue un joven de gran talento y trabajó obras primorosas y que, tras acabar su enseñanza, volvió a Zaragoza $^{29}$. En Madrid, ingresó en la Real Academia de San Fernando el 16-11-1778, pensionado por la Real Sociedad Económica Aragonesa de Amigos del País de Zaragoza. Asistió a las enseñanzas de la Real Escuela de Platería de Antonio Martínez, donde le visitó el conde de Torrescasas, don José de Villalpando y Rozas como delegado de la Real Sociedad Económica en el viaje que realizó a Madrid en agosto de 1783, para observar los progresos que estaba haciendo en la Escuela ${ }^{30}$. En 25 de mayo de 1784 se registra en las actas de la Real Sociedad Económica un contrato para que enseñase en Zaragoza las técnicas de la joyería aprendidas en Madrid con Antonio Martínez durante el tiempo en

29 LARRUGA Y BONETA, E., Memorias políticas y económicas..., Madrid: Antonio Espinosa, t. IV, 1789, p.124.

30 FORNIÉS CASALS, J.F., La otra nobleza titulada en la Real Sociedad Económica Aragonesa de Amigos del País en tiempos del conde de Aranda (1776-1798). En: El conde de Aranda y la nobleza española en el Antiguo Régimen (coord. M.J. CASAÚS BALLESTER), Zaragoza: Fernando el Católico, 2009, p. 250. 
que estuvo pensionado por la Sociedad ${ }^{31}$. Ha de ser uno de los cuatro discípulos de la Escuela que cita como fallecidos un informe del fiscal de la Real Junta de Comercio de febrero de $1787^{32}$.

\section{ORZAIS, Antonio, (o). Zaragoza. Antes de 1660-post1706.}

Cumplió su aprendizaje en Zaragoza con Nicolás Barón, platero de oro. En Madrid, trabajó desde 1660 con Lamberto Haller, platero real. Fue aprobado el 3-7-1670; dibujó e hizo una venera de Calatrava con su copetico de oro y diamantes. En el donativo que hicieron los plateros al rey en 1694 para la campaña del año figura con 120 reales, cifra notable para los que no habían ocupado oficios en la Congregación de San Eloy. Poco después ocupó varios: candidato a mayordomo en 1698 no elegido, mayordomo en 1702, contador en 1703 y aprobador desde 1-7-1703 a 27-6-1706. Es posible que fuera hermano de Felipe, platero aprobado en Zaragoza el mismo año 1670.

\section{PÉREZ, Mariano. Zaragoza. 1779-post 1808.}

Aparece en la relación de mancebos elaborada a 1-1-1808, que señala su fecha y lugar de nacimiento; figura soltero y viviendo en la calle de San Juan, 14.

\section{PÉREZ, Pedro (p). Zaragoza. Doc. 1636-1651.}

Trajo recados de Zaragoza y fue aprobado como maestro platero de plata el 1-7-1636; dibujó e hizo una ruciadera en el examen. Ingresó en la Congregación de San Eloy el 27-6-1638. En 1645 se le encargó que llevara un libro de piezas perdidas y hurtadas y que pidiera los lunes para los pobres. Fue elegido mayordomo en 1650 y pasó a diputado al año siguiente. Sin embargo de lo común de su nombre y apellido, ha de ser el platero al que repartieron 300 reales para el adorno de la Platería en 1649 con motivo de la entrada solemne de la reina Mariana. Sólo seis plateros figuran con mayor cantidad, lo que indica su próspera situación.

\section{PUGEO, Juan José (o). Belchite (Zaragoza) 1748-1815/1824.}

Fue aprendiz en Zaragoza con Bernardo Espinós y mancebo con Manuel Soler, José Salvate y Joaquín Zunzarren según certificación de Bernardo Lorda, José Sanasí y Joaquín de Fuentes, secretario, mayordomo mayor y mayordomo menor de la Congregación zaragozana. El 27-8-1772 pidió la aprobación en Madrid, el 27-9-1772 pasó a practicar y dibujó una pieza de garganta con su colgante en forma de herradura y piocha compañera y una sortija y la sacó de fuego y engastó de brazo abierto orlada toda de diamantes y rosas con hoja de plata, hasta su conclusión. Recibió la aprobación el 26-10-1772. El 6-7-1773 testificó sobre Joaquín Gil, afirmando que aprendieron en la misma casa, el obrador de Espinós. Estaba entonces casado con María de Dueñas y Briones, seguramente hermana

31 FORNIÉS CASALS, J.F., Fuentes para el estudio de la sociedad y la economía aragonesas entre 1776 y 1808 . Los documentos citados en las Actas de la Real Sociedad Económica Aragonesa de Amigos del País. En Cuadernos de Historia Jerónimo Zurita, 35-36, 1979, p.275, nº 700 .

32 CRUZ VAldovinos, J.M., Antonio Martínez y la Real Escuela y Fábrica de Platería. 1749-1813, Madrid, 2020, inédito, pp. 67, 91-92. 


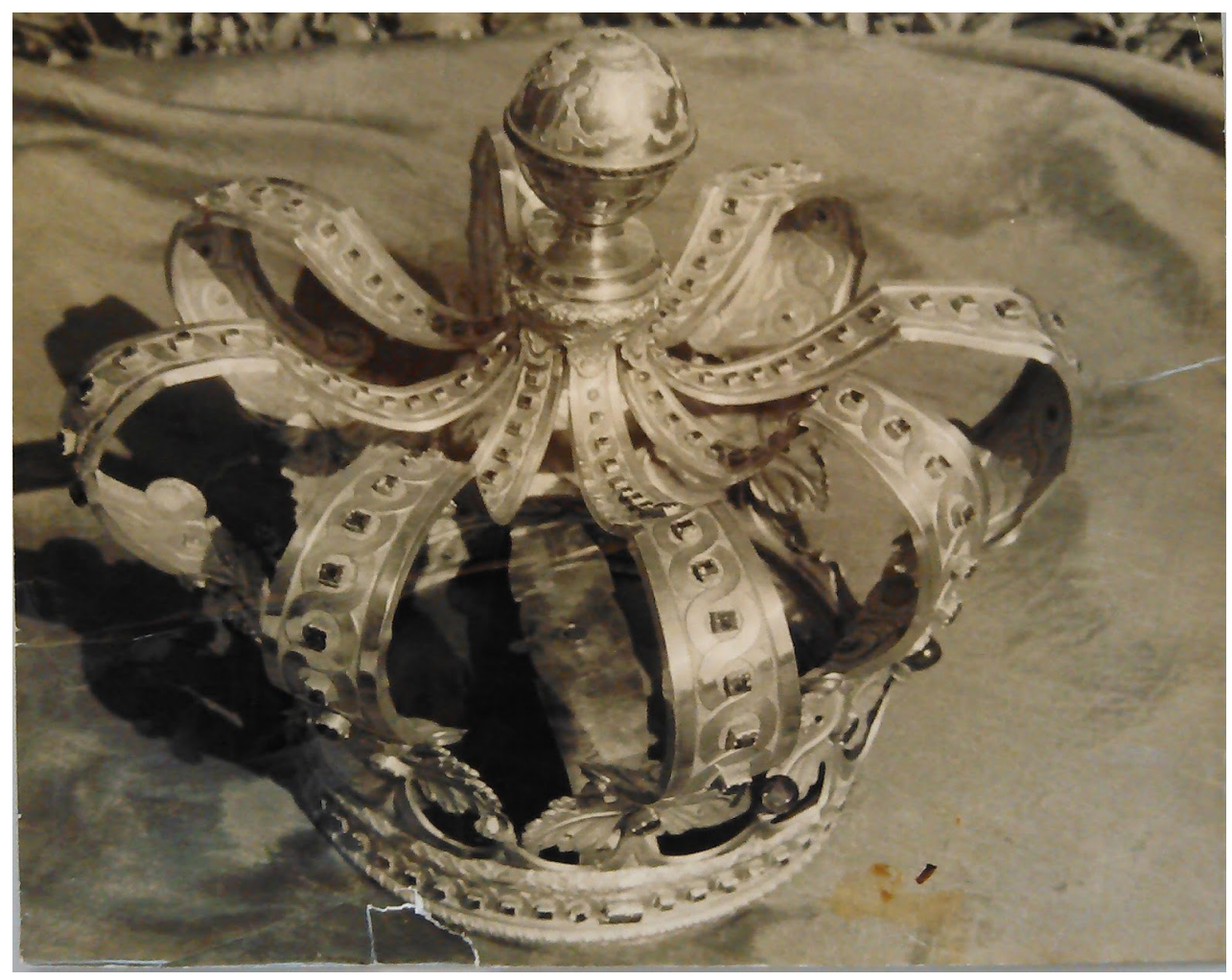

Fig. 2: Juan José Pugeo. Corona de la Virgen del Tránsito. 1785. Iglesia de Santo Domingo, Cartagena de Indias.

del platero José; se sabe que tuvo una hija llamada Ramona ${ }^{33}$. Vivían en la calle de los Tintes, casa propiedad de la congregación del Santísimo Cristo de San Ginés.

Pagó las siguientes cantidades, relativamente importantes, por la alcabala: 1765-1773, 30; $1774-$ 1775,$75 ; 1776-1778,75 ; 1779-1780,50 ; 1781-1782$, 50; 1783-1784, 80; 1785-1786, 90; 1787, 45. En 1783 contribuyó con 30 reales al donativo solicitado por el Rey y en 1793 con 15 reales en la oferta mensual a Carlos IV. En el donativo por las urgencias del Reino solicitado en 1815 figura con 40 reales, cantidad relativamente baja entre 213 contribuyentes. No aparece en el subsidio de Comercio de 1825 .

Tuvo los siguientes aprendices: su sobrino, Agustín de Dueñas y Briones, con cédula de 31-5-1777, contando desde 31-1-1774, aprobado como maestro el 26-11-1784; Antonio Fernández Moreno, de Navalcarnero, con cédula de 22-10-1778, maestro el 22-5-1798; su hijo Isidoro, para el que obtuvo cédula el 14-5-1793; Matías Lizarbe, quizá miembro de la familia de plateros zaragozanos de ese apellido conocidos en el siglo XVII, con cédula de 27-3-1799, contando desde 1-1-1799. Tuvo su obrador en la calle del Mesón de Paños 17, $3^{\circ}$ (manzana 418) y tenía la casa en la calle de las Fuentes 2, $2^{\circ}$ (manzana 414). En 1808 vivía, casado, en la calle de San Ginés 7.

Obra firmada y fechada en 1785 es la corona con imperiales para la imagen de la Virgen del Tránsito (iglesia de Santo Domingo, Cartagena de Indias), perteneciente a la familia de Andrés-Torres, regalada por la marquesa de Valdehoyos, doña María Francisca de Miranda Gómez, a su amiga Nicolasa García de Torres, perteneciente a aquella familia ${ }^{34}$ (Fig. 2).

33 Casada con Manuel Bernardino García Suelto, oficial del Ministerio del Interior con el rey José en 1810 y madre de dos hijos: GIL NOVALES, A., Diccionario biográfico de España, 1808-1833, De los orígenes del liberalismo a la Reacción absolutista, Madrid: Fundación Mapfre, 2010, p.1265.

34 https:/genealogiasdecartagena.blogspot.com/2016/07/la-virgen-del-transito-traves-de-la.html. (Consulta 10 junio 2020). De oro con 227 esmeraldas y peso de 1247 gr. Se ilustra con fotografía, pero no se transcribe la inscripción. 


\section{PUYOL, Mariano (p). Zaragoza. Doc. 1819.}

Presentó certificación el 27-5-1819 de haber aprendido y ser oficial en Zaragoza. Luego trabajó como mancebo en Madrid. Hizo entonces el examen teórico y pasó a hacer la pieza que le tocara en suerte o la que dijera el aprobador. Hizo un copón mediano y fue aprobado el 30-6-1819. No figura en los subsidios de Comercio de 1825 y 1827.

\section{RODRÍGUEZ, Silvestre (o). Zaragoza. Doc. 1791-1797.}

Aprendió en Zaragoza e ingresó en la Hermandad de Mancebos el 24-5-1791. Solicitó la aprobación como maestro el 30-6-1797 e hizo el examen el 28-8 siguiente; dibujó una borla e hizo un medallón (n 11 del libro de Dibujos). Fue aprobado como maestro platero de oro el 27-9-1797.

\section{ROSEROL, Antonio (p). Lérida. Doc. 1740-post. 1754.}

Aprendió y fue aprobado en Zaragoza. Asistió a la junta general de la Congregación de San Eloy el 22-1-1740, si bien no recibió la aprobación como maestro hasta el 8 de marzo siguiente. Se anotó entonces que era natural de Lérida del obispado de Zaragoza.

Sólo pagó alcabala por el bienio 1751-1752, 4 reales, si bien estuvo en Madrid algún tiempo más, pero el siguiente repartimiento corresponde al septenio 1753-1759, momento en que hacía tiempo que se había ausentado.

Fue su oficial y quizá también su aprendiz el madrileño Francisco Antonio Cortijo y Mondragón, que pasó a practicar el 28-1-1752 y recibió la aprobación como maestro platero de plata el 31-10-1752.

Se conocen dos piezas suyas marcadas en Madrid. Una cruz procesional (catedral de Jaén) marcada en 1740/1747, y un rostrillo en Agudo (Ciudad Real) con marca utilizada entre 1754 y 1759. Su marca es RO/SErOL. Poco después de 1754 debió de marchar a México, donde marcó un cáliz que se encuentra en la catedral de Jaén y un jarro de pico (colección Cavero), con marca personal ROSE/ROL.

Tuvo que suceder en 1755, recién llegado a México, su patrocinio de la edición de un sermón del agustino Francisco de San Pedro ${ }^{35}$. En la dedicatoria se titula "platero de su excelencia", que, en el contexto de los escritos autorizantes, tenía que ser don Francisco Guémez de Horcasitas, todavía virrey — cesó a mediados de 1755 y volvió a España a fines de ese año- que había autorizado la edición del impreso en 29 de agosto de 1747, poco después de haberse pronunciado el sermón ${ }^{36}$. Es probable que el virrey —que se había enfrentado a agustinos y dominicos, de acuerdo con el obis-

35 SAN PEDRO, Fray F. de, La nada más gloriosa, sermón panegírico que en el quinto día de la infraoctava de San Bernardo predicó...este año de 1747 el M.R.P.... Sácalo a luz: D. Antonio Roserol, Platero de su Excia. Y lo dedica a D. Juan de Salmonte, y Tabuada, vecino, y del Comercio de esta Ciudad. México: Imprenta de la Viuda de D. Joseph de Hogal, 1747.

36 EGUIARTE BENDÍMEZ, E. A., El P. fr. Francisco de San Pedro, OAR, y su sermón «La nada más gloriosa» (México, 1747). En: Recollectio, 37, 2014, pp. 101-145.No se ha planteado la posibilidad de que Roserol pagara la edición a su llegada a México, que se produciría entre 1754 y 1755 . La dedicatoria, a diferencia de las aprobaciones y licencias, que se fechan entre agosto y septiembre de 1747, lo mismo que la edición, no está datada y, extrañamente, se escribe para justificar que se dedique no al autor de la homilía -a quien dice que conoce y es su amigo, aunque murió a principio de 1751- sino al importante comerciante y prestamista don Juan de Salmonte y Taboada, que llegó a ser alcalde ordinario de la ciudad, y que realizó un importante legado de piezas de plata a San Vicente de Burrés (cercano a Arzúa, en La Coruña) donde había nacido (expediente ES.41091.AGI/10//CONTRATACION,5645), estudiado por SÁNCHEZ CORTEGANA, J. M. y MACÍAS, R., Mandas testamentarias y plata labrada en Indias. Los legados de Domingo José Suárez y Juan de Salmonte y Taboada a Galicia en el siglo XVIII. En: Arte y patrimonio en España y América, Montevideo: Universidad de la República, 2014, pp.73-88. 
po, al encomendar al clero secular algunas vacantes de doctrinas de indios que antes regentaban los agustinos en México - quisiera congraciarse con la orden agustina al publicar el sermón, si bien encubriendo su nombre bajo el de su platero.

\section{SALA Y LAMARCA, Andrés de la (o). Zaragoza. 1696-1758/1760.}

A la vista de las detalladas páginas que le dedicó la doctora Aranda Huete, nos limitamos a añadir varias noticias y recoger en resumen algunas de las incluidas en su publicación ${ }^{37}$.

Hijo de Antonio y María, casó en 1716 con Ventura Visgres, hermana de Santiago, también platero, con quien seguramente había aprendido. Admitido a examen el 8-3-1716, fue aprobado como platero de oro en su ciudad natal después de hacer un cintillo de ocho diamantes y una esmeralda. En junio del mismo año firmó las capitulaciones matrimoniales. En 1717 compró varias piezas — sortijas, cruces, hebillas y pendientes - a un comerciante francés que las presentó a la Junta del Colegio de Zaragoza para que verificara la ley, resultando faltas de ella por lo que se decidió que fueran destruidas. En 1737 casó en segundas nupcias con una viuda, Francisca García, quizá ya en Madrid. El 28-12-1739 recibió la aprobación como maestro en la Congregación de San Eloy de Madrid. En 1741, su mujer le acusó de malos tratos y abandono del domicilio conyugal, de que no había aportado nada al matrimonio y de agotar los caudales de su dote, por lo que solicitó su prisión, que tuvo lugar el 25-12-1642, junto al embargo de sus bienes. Vivían en la calle de los Bordadores, con varios oficiales, pues allí tenía su obrador. Había obtenido plaza de criado supernumerario de la Real Cerería. Afirmó que había aportado al matrimonio 55 quilates de esmeraldas y algunas joyas que estaban empeñadas. Después de un acuerdo con su mujer, fue puesto en libertad el 22-3-1743 y las alhajas desempeñadas. Desde 1753 a 1757 hay noticias de que suministró al platero Manuel González Cordón piedras preciosas que empleó en joyas para la duquesa del Infantado. Satisfizo la alcabala sólo por el bienio 1751-1752, 50 reales. No aparece en el reparto de 1753-1759 y tampoco contribuyó al gasto del adorno de la Platería en 1760, por lo que suponemos que murió algo después de 1757 o se ausentó de la corte.

\section{SALATÍ, Esteban (p). Cardona (Barcelona). Doc. 1729.}

Aprendió con José Albéniz en Zaragoza y recibió la aprobación como maestro en Madrid el 10-81729. No se le vuelve a mencionar.

\section{SAMPER FUENTES, Félix (o). Tarazona (Zaragoza) 1810-1877.}

Existen varios trabajos en que se reúnen noticias de este platero ${ }^{38}$ por lo que nos limitaremos a señalar algunos aspectos principales y a añadir noticias inéditas.

Hijo de José, de Tarazona y de Cayetana, de Borja. Hubo de venir joven a Madrid, pues en la Corte cumplió desde 1829, al menos, los seis años de aprendiz y los cuatro de mancebo que exigían las ordenanzas antes de acceder a la aprobación; estuvo en la Real Fábrica de Platería y en los obradores de Francisco Moratilla y Juan Almarza. En 1834 formó parte de la Milicia Urbana, figurando como

37 ARANDA HUETE, A., ref..5, pp.314-316.

38 LÁZARO MILLA, N., ref. 6, 2013 y PÉREZ SÁNCHEZ, M. y CAMACHO CÁRDENAS, E.M., ref. 7, pp. 431-445. Recoge noticias publicadas por Fernando Martín, Santiago Alcolea, Matías Fernández García y José Manuel Cruz Valdovinos. 
platero y broncista. Pero el 27-11-1838, Antonio Tomé de Ondarreta, vecino de Madrid, solicitó al Colegio cédula de aprendiz para su hijo Simón, que estaba en el obrador de Samper, advirtiendo que si su maestro no accedía recurriría a la autoridad; el Colegio contestó que Samper no estaba reconocido como maestro y, por tanto, no podía solicitar la cédula. Quizá por este incidente, el 31-5-1839 Samper presentó certificación de haber cumplido los años de aprendiz y mancebo y pasó a examen. El 27-6-1839 dibujó un medallón e hizo un alfiler para engastar diamantes brillantes al aire, forrado de oro. El 30-8-1839 recibió la aprobación como maestro platero de oro o diamantista. En 1845 abrió un moderno gabinete contiguo a su tienda en la calle del Prado $\mathrm{n}^{\circ} 7$, donde también tenía su vivienda desde 1839 al menos. Desde 1844 había trabajado para Isabel II y en 1847 fue nombrado diamantista honorario de Cámara de la Reina. En 1850 abrió un nuevo establecimiento en la calle del Carmen frente a la de la Salud, y en 1864 hizo otro tanto en París, donde murió. Las vicisitudes y categoría de los establecimientos de Madrid y París han sido minuciosamente estudiadas, así como la referencia a los clientes de mayor importancia por lo que evitamos repetir estos datos.

Cuando tuvo lugar su aprobación llevaba alrededor de tres años casado con la parisina Ana Leclavart, hija de Carlos (Perona, Picardía) y de Rosa de la Vega Campuzano (Sevilla). Tuvieron tres hijas, Elisa (fallecida el 29-3-1838, con 18 meses), María (bautizada el 24-1-1839) y Enriqueta (muerta el 24-8-1845, al parecer también con año y medio), y un hijo, Federico, que fue comerciante en París y que en 1891 quedó viudo de Rosario Camacho Fernández. Desde 1840 el diamantista figura inscrito entre los contribuyentes a la Sociedad de Socorros Mutuos de artífices plateros, con cuota mensual de 4 reales; solo Juan Sellán aparece por delante inscrito desde 1838. Cuando Félix murió, le sucedió su hijo Federico en la suscripción.

Además de las joyas y condecoraciones que han sido dadas a conocer hay piezas de plata que llevan la marca F. /SAMPER. Son, por lo menos, las siguientes: candeleros 1845 (comercio), chofeta de 1850 (Fernando Durán, mayo 1985), cálices de 1856 (catedral de Alicante) y de 1858 (San Andrés de Toledo, donado al Santo Cristo de la Salud por doña Guadalupe Uztáriz de Figueroa y sus hijas) y candeleros de 1858 (Enciclopedia).

\section{SANDOVAL, Antonio (o). Zaragoza. Doc. 1753-1793.}

Aprendió en Zaragoza y estuvo luego más de once años en Madrid en el obrador de Antonio Albero. En 1760 contribuyó como mancebo con 20 reales al gasto por el adorno de la Platería en la entrada solemne de Carlos III y María Amalia. Pasó a practicar el 27-8-1764 e hizo una pieza de garganta, piocha, muelle para pulsera y anillo; recibió la aprobación como maestro el 28-9-1764. Pagó cantidades medianas por la alcabala, incluso cuando aún era mancebo:1753-1759, 20; 1760-1764, 30; 1765-1773, 108; 1774-1775, 22; 1776-1778, 30; 1779-1780, 22; 1781-1782, 22; 1783-1784, 30; 1785-1786, 30; 1787, 12. No contribuyó en 1783 al donativo solicitado por el rey y en 1793 lo hizo con 15 reales en la oferta mensual. No figura en la relación de plateros de 1808; seguramente había fallecido.

Pidió cédula para varios aprendices: Miguel del Campo Montemayor, 26-3-1771 (la había solicitado el padre del aspirante el 27-2-1771); ingresó en la Hermandad de Mancebos en 1777 y recibió la aprobación como maestro el 21-2-1785. José María Agustín del Castillo, 27-2-1778, contando el tiempo desde 24-6-1777; el madrileño Pedro Pablo Antonio Benito, 6-4-1780, contando el tiempo 
desde 12-3-1780 y recibiendo la aprobación de maestro el 27-10-1796. Manuel Julián Menéndez, 22-6-1786, aprobado el 24-5-1804. Julián María Ducanel, 31-7-1793, contando el tiempo desde 127-1793.

Tuvo casa en la calle de los Milaneses 1 (manzana 417) y obrador en la calle de San Miguel 9, $3^{\circ}$ (manzana 171).

\section{SERRANO, Pedro. ¿Zaragoza? Doc. 1822-1827.}

Aprendió en Zaragoza y fue reconocido como mancebo en Madrid el 27-8-1822. No consta que llegara a aprobarse como maestro, pero en 1827 figura en el Subsidio de Comercio con 30 reales y vivía en la calle de Toledo al lado de la Estafeta.

\section{SINESTROSA, Tomás. ¿Zaragoza? Doc. 1802.}

Aprendió en Zaragoza y fue reconocido como mancebo en Madrid el 29-11-1802. No aparece en la relación de mancebos de 1808 .

\section{SOLER, Andrés (o). Zaragoza. Doc. 1755-1771.}

Aprendió en Zaragoza con Diego Álvarez. El 25-4-1755 pasó a practicar e hizo varios dibujos; recibió la aprobación como maestro el 28-5-1755. Sólo aparece en las listas de pagos por la alcabala en dos repartos, 1753-1759, 40 y 1760-1764, 20, En 1760 figura con 40 reales en la contribución al gasto para el adorno de la Platería en la entrada de Carlos III y María Amalia.

Solicitó cédula para su aprendiz Saturnino Rodríguez, de Pinto (Madrid) el 6-6-1767, aunque no se le debió conceder, porque el 23-7-1770 la pidió Manuel Rodríguez y se le otorgó. El 30-4-1770 pidió cédula para Ventura Guerin, de Perpiñán; pasaron los papeles a los aprobadores, pero tampoco consta que se la concedieran. Por fin, el 29-1-1771 solicitó certificación de ser maestro aprobado, porque se iba a ausentar a Talavera y le convenía presentarla allí; se accedió a lo que solicitaba, por lo que cabe que continuara su actividad en la ciudad toledana, donde por ahora no ha sido documentado.

\section{SUÑER, Francisco (o). Zaragoza. Doc. 1772-1773.}

Aprendió con Francisco Llopar, platero aprobado en Zaragoza. El 26-10-1772 presentó los papeles a los aprobadores manifestando además que había trabajado en diversas partes de la Corte. El 2611-1772 pasó a practicar y dibujó un ramito para el lado y otro de una piocha, hizo todos los moldes de la piocha y la sacó de fuego, la repasó y engastó algunas piedras de diamantes en pieza diferente. Recibió la aprobación como maestro el 18-12-1772. Satisfizo la alcabala en el periodo 1765-1773 con 15 reales, pues no llevaba sino unos pocos meses aprobado, pero no figura en el reparto del bienio siguiente. El 29-11-1773 pidió cédula de aprendiz para Pedro Domínguez, de Medina del Campo. El 6-7-1773 testificó que había conocido a Joaquín Gil de Zaragoza. En esa fecha, Suñer estaba casado con Juana Zarza y vivía en la calle de Atocha, frente a la iglesia de San Sebastián. No figura en los donativos de 1783 y 1793. 


\section{SUÑER, José (o). Alcañiz (Teruel) Doc. 1767-1782/1783.}

Aprendió en Zaragoza con Andrés Querol y trabajó en Madrid más de cuatro años. E1 29-10-1771 solicitó la aprobación en Madrid. Dibujó una piocha de flores y cogollos y realizó una sortija de flor de diamantes y una esmeralda. Recibió la aprobación como maestro el 19-12-1772.

Satisfizo la alcabala en los periodos siguientes: 1765-1773, 30; 1774-1775, 28; 1776-1778, 40; 1779-1780, 28; 1781-1782, 20. No contribuyó en 1783 al donativo solicitado por el Rey aunque su nombre figura en la lista. Tenía casa y tienda en la calle de Fuencarral 1 (manzana 344).

E1 28-2-1772 pidió cédula de aprendiz para Manuel López Recuero, de Camarena (Toledo), pero se acordó que no se concedería hasta que trajera información de José Moragull que le había despedido antes de mayo de 1771; no se le concedió hasta el 26-10-1773 después de haber seguido Recuero una instancia ante la Sala de Alcaldes y presentado su testimonio. E1 30-8-1773 pidió cédula para su hermano Jerónimo, de Zaragoza. El 15-6-1778 recibió la cédula para Juan Esteban Garrido, contando el tiempo hasta el 1-2-1777 y el 5-6-1781 la de José Vicente Pedraza, contándole desde 8-6-1776, pues había estado antes con Antonio de Lara.

\section{TIRADO, José (o). Borja (Zaragoza) Doc. 1778-1779.}

El 23-7-1779 fue reconocido como aprendiz de Miguel de Alba, corriendo el tiempo desde el 1-101778.

\section{USED, Melchor (p). Huesca. 1746-1799/1807.}

En enero de 1774 se matriculó en la Real Academia de San Fernando con 27 años. Había sido aprendiz de platero en Huesca con Nicolás Julián y luego trabajo en Zaragoza y Madrid como mancebo, seguramente al tiempo que estudiaba en la Academia. El 28-1-1778 solicitó la aprobación como maestro; el 29-3-1778 pasó a practicar; dibujó un cáliz sombreado de tinta de China y sobrepuestos de oro e hizo unas despabiladeras de plata y sus moldes; recibió la aprobación el 29-4-1778.

Satisfizo pequeñas cantidades en el pago de la alcabala: 1776-1778: 4; 1779-1780: 8; 1781-1782: 10; 1783-1784: 10; 1785-1786: 10; 1787: 12. Contribuyó con 4 reales en 1783 al donativo solicitado por el Rey y en 1793 lo hizo con 8 reales en la oferta mensual. Tuvo tienda en la calle de la Cruz, 7 (manzana 213).

Recibió numerosos aprendices aunque no consta que llegara a aprobarse ninguno. José Antonio Ximénez de Navalcarnero (Madrid), recibió cédula el 2-12-1779, corriendo el tiempo desde 17-111779, pero luego se indica que se le tachó. Gabriel José Cardeña de Madrid, hijo de Felipe que no consta que fuera platero, 26-4-1781 y contando desde 9-3-1781. Leonardo José María Tejero, de Madrid, 10-4-1783, corriendo desde 30-9-1782. Pedro Lezo, 30-3-1789. Julián Moreno, 21-3-1794, contando desde 4-2-1794. Vicente López Naranjo, 29-4-1795 aunque corría desde 26-3-1795. Martín Herrante, 27-5-1796, contando desde 13-4-1793. Francisco Escobar, 20-12-1796, contando desde 16-11-1796. Y Juan Solís, 28-11-1799 y corría desde 1-7-1799. La falta de perseverancia de tantos aprendices no es fácil de explicar; las bajas cantidades repartidas por la alcabala, así como que no se conozca pieza alguna con su marca lleva a pensar que su actividad fue escasa. 


\section{VAL, Antonio. Zaragoza. Doc. 1779.}

Ingresó en la Hermandad de Mancebos el 1-5-1779; había aprendido en Zaragoza con Onofre Lovera.

\section{VENATIS, Marco Antonio de (p). Zaragoza. H. 1600-post 1649.}

Aprendió en Madrid desde antes de 1609 e ingresó en la Hermandad de Mancebos el 16-12-1619. Marchó después a la Ciudad de los Reyes en Perú. Regresó a la Corte y fue aprobado como maestro platero de plata el 2-12-1639 y pasó a diputado en 1640. Casó en 1626 con Isabel de Usategui, hija de Andrés Alonso, de familia de plateros y recibió una prebenda de 50 ducados de la memoria instituida por Martín Fernández a favor de la Cofradía. En el reparto para el adorno de la Platería en la entrada solemne de la reina Mariana en 1649 le señalaron 250 reales, con solo 14 plateros con mayor cantidad, lo que significa una situación económica sobresaliente.

\section{VILLASENDRA, Francisco Pascual (o). Zaragoza. 1750/1753-post 1808.}

Aprendió en Zaragoza con José Salvate. Solicitó la aprobación como maestro en Madrid el 19-121771 y pasó a practicar el 28-1-1772; dibujó una pieza de garganta que luego sacó de fuego e hizo los moldes de palmas y engastes con ocho piedras venturinas; recibió la aprobación el 28-2-1772. El 6-7-1773 testificó sobre Joaquín Gil con quien se crió en Zaragoza y que sus padres y abuelos eran labradores. En esa fecha estaba casado con Juana Sotomayor y vivía en la calle de Jacometrezo "encima de una espadería". En 1786 figura viviendo en la calle de la Flor Baja, 5, 2 y el 1-1-1808 en Silva, 9, y seguía casado.

Pagó cantidades muy bajas por la alcabala: 1765-1773: 15; 1774-1775: 14; 1776-1778: 10; 17791780: 6; 1781-1782: 6, 1783-1784: 6; 1785-1786: 4 y 1787: 2 . No figura en la lista de1783 del donativo solicitado por el Rey y en la oferta mensual de 1793 a Carlos IV lo hizo con 5 reales.

En 1786 consta que trabajaba a jornal, por lo que no extraña que no tuviera más que un aprendiz que llegara a maestro: Bernabé Antonio Hernández, de Móstoles (Madrid), al que se dio cédula el 15-3-1784, corriendo el tiempo desde 25-1-1784; fue aprobado el 30-3-1802. Los otros aprendices que se le conocen fueron tres hijos: Eugenio, el 1-11-1793 contando desde 30-10-1793; Remigio, 306-1797, contando desde 23-5-1797; y Prudencio, 29-8-1799, contando desde 1-8-1799.

\section{XIMÉNEZ DE ARAGÜÉS, Juan Antonio (o). Zaragoza. Doc. 1640-1649.}

Era vecino de Madrid en 1640. Presentó una carta de los mayordomos de Zaragoza en la que suponemos certificaban el aprendizaje cumplido allí, pues el 31-1-1643 recibió la aprobación como maestro: dibujó e hizo un "retablico" de oro con una iluminación, tallada de trasflor y esmaltada de colores. Para costear el adorno de los plateros en la entrada solemne de Mariana en 1649 le repartieron 55 reales, una cantidad mediana, pues 81 plateros de 142 pagaron más. No figura en el donativo al Rey de 1694. 
58. YANGUAS, Francisco de (p). Zaragoza. Doc. 1627-1649.

Vecino de Madrid en 1627. Aprobado como maestro el 17-11-1639 tras hacer un atril todo calado de lima. Para el gasto de la entrada de la reina Mariana en 1649 se le repartieron 20 reales, igualando a otros seis y con sólo tres plateros con cantidades menores. No figura en el donativo de 1694 .

\section{YOLDI Y ESPARCILLERAS, Antonio Agustín Miguel de (p). Zaragoza. 1702-post. 1756.}

Bautizado el 11-1-1702 en la iglesia de la Magdalena de Zaragoza. Hijo de Martín, nacido en Pamplona el 14-8-1655 y de Josefa, en Báguena (Teruel) el 25-8-1668; tuvieron dos hijos más, llamados Jaime y José. En 1728, los plateros Antonio García y José Godó, de Zaragoza, certificaron que Yoldi estuvo de aprendiz y mancebo con Lamberto Garro con toda satisfacción, que su padre, Martín, llevaba 40 años en Zaragoza desde que dejó Pamplona y que durante más de 20 años había sido contador del Pósito y Graneros y continuaba siéndolo, y que en 1710 sufrió muchos días de prisión y atropellamiento por las tropas enemigas. Su hijo José era oficial de la Contaduría general del ejército y rentas reales del reino de Aragón.

E1 24-6-1728 ingresó en la Hermandad de Mancebos de Madrid. No consta en qué obrador trabajó y, desde luego, no recibió aprobación como maestro.

Su vida dio un giro inesperado, pues, en 1756, cuando probó su hidalguía para ingresar en la orden de Santiago - cuyas pruebas recogen su genealogía hasta el tercer grado en línea directa - era comandante general de Mar y Tierra de los resguardos de todas las rentas en la ciudad de Cádiz, su bahía y jurisdicción ${ }^{39}$.

\section{Relación de plateros citados activos en Zaragoza}

Agramón, Valero

Albéniz, v. Pérez

Álvarez, Diego

Arque, Sebastián

Arragueta, Miguel

Asso. Pedro

Barón, Nicolás

Bestenovi, Antonio

Dargallo, Antonio

Dieste, Diego

Espinós, Bernardo

Estrada, Domingo

Fuentes, Joaquín
Fuentes, Pedro

García, Antonio

Garro, Bernardo

Godó, José

Leredo, Juan

Llopar, Francisco

López, Domingo

Lorda,V. Bernardo

Losilla, Miguel

Lovera, Onofre

Menteguía, Francisco

Moliner, Clemente

Moliner, Francisco
Noble, Raimundo

Orzáiz, Felipe

Pérez de Albéniz, José

Querol, Andrés

Rosell, Juan

Roses, Manuel

Salvate, José

Sanasi, José

Sanz, Francisco

Soler, Manuel

Visgres, Santiago

Xea, Rudesindo

Zunzarren, Joaquín

39 CADENAS Y VICENT, V., refer.10, nº1384. 


\section{Bibliografía}

ARANDA HUETE, Amelia, La joyería en la Corte durante el reinado de Felipe Ve Isabel de Farnesio. Tesis Doctoral, Madrid: Universidad Complutense de Madrid, 1996.

ARANDA HUETE, Amelia, La joyería en la Corte durante el reinado de Felipe V e Isabel de Farnesio. Madrid: Fundación Universitaria Española, 1999.

ARCO, Ricardo del, Orfebres oscenses (siglos XVI, XVII y XVIII). Revista de la Academia de Buenas Letras. 1912, $\mathrm{n}^{\circ}$ 47, Vol. 6 pp. 374-381.

CADENAS Y VICENT, Vicente, Caballeros de la orden de Santiago. Siglo XVIII, Madrid: Hidalguía, 1979.

CRUZ VALDOVINOS, José Manuel, La platería y los plateros de Madrid desde 1624 hasta 1695, Tesis de licenciatura inédita, Pamplona: Universidad de Navarra, 1968.

CRUZ VALDOVINOS, José Manuel, El arte de la plata. Colección Hernández-Mora Zapata, Murcia: Fundación Cajamurcia, 2006.

CRUZ VALDOVINOS, José Manuel, Plateros aprobados e incorporados al Colegio de San Eloy de Madrid (1 de enero de 1808). En: Estudios de Platería (coord. J. RIVAS CARMONA), Murcia: Cajamurcia, 2012, pp. 161-176.

CRUZ VALDOVINOS, José Manuel, Relación de plateros activos en Madrid en 1861. En: Estudios de Platería (coord. J. RIVAS CARMONA), Murcia: Universidad de Murcia, 2013, pp. 161-172.

CRUZ VALDOVINOS, José Manuel, ABAD VIELA, Javier y MONTALVO MARTÍN, Francisco Javier, Platería antigua española y virreinal americana (siglos XV-XIX), Murcia: Fundación Cajamurcia, 2019.

CRUZ VALDOVINOS, José Manuel, Antonio Martínez y la Real Escuela y Fábrica de Platería. 1749-1813, Madrid, 2020 , inédito.

EGUIARTE BENDÍMEZ, Enrique A., El P. fr. Francisco de San Pedro, OAR, y su sermón «La nada más gloriosa» (México, 1747). En: Recollectio, 37, 2014, pp. 101-145.

ESTEBAN LÓPEZ, Natividad, Orfebrería de Sigüenza y Atienza, Tesis doctoral inédita. Madrid: Universidad Complutense de Madrid, 1992.

ESTEBAN LORENTE, Juan Francisco, La platería de Zaragoza en los siglos XVII y XVIII, 3 vols., Ministerio de Cultura, Dirección General de Patrimonio Artístico, Archivos y Bibliotecas, Centro Nacional de Información Artística, Arqueológica y Etnológica, 1981.

FERNÁNDEZ GARCÍA, Matías, Parroquias madrileñas de San Martín y San Pedro el Real. Algunos personajes de su archivo, Madrid: Caparrós, 2004. 
FORNIÉS CASALS, José Francisco, "Fuentes para el estudio de la sociedad y la economía aragonesas entre 1776 y 1808. Los documentos citados en las Actas de la Real Sociedad Económica Aragonesa de Amigos del País". En: Cuadernos de Historia Jerónimo Zurita, 35-36, 1979, pp. 173-211.

FORNIÉS CASALS, José Francisco, La otra nobleza titulada en la Real Sociedad Económica Aragonesa de Amigos del País en tiempos del conde de Aranda (1776-1798). En El conde de Aranda y la nobleza española en el Antiguo Régimen (coord. M. J. CASAÚS BALLESTER), Zaragoza: Fernando el Católico, 2009, pp. 243-274.

GIL NOVALES, Alberto, Diccionario biográfico de España, 1808-1833, De los orígenes del liberalismo a la Reacción absolutista, Madrid: Fundación Mapfre, 2010.

HERRERO GÓMEZ, Javier y MÁRQUEZ MUÑOZ, José Ángel, La platería en Almazán, Soria: Ayuntamiento, 1994.

LARRUGA Y BONETA, Eugenio, Memorias políticas y económicas ..., Madrid: Antonio Espinosa, 1789.

LÁZARO MILlA, Nuria, Félix Samper. Historia de un diamantista, Madrid: Museo del Romanticismo, 2013.

MONTALVO MARTÍN, Francisco Javier, El platero segoviano Juan de la Cruz Benito Gómez (1733-1810). En: Estudios de Platería (Coords. J. RIVAS CARMONA e I. J. GARCÍA ZAPATA), Murcia: Cajamurcia, 2019, pp. $397-408$.

ORBE SIVATTE, Mercedes, Platería en el taller de Pamplona en los siglos del Barroco, Pamplona: Gobierno de Navarra, 1999.

PARDO CANALÍS, Enrique, Los registros de matrícula de la Academia de San Fernando de 1752 a 1815, Madrid: CSIC, 1962.

PÉREZ SÁNCHEZ, Manuel y CAMACHO CÁRDENAS, Enrique, Consideración social y proyección internacional de un diamantista español: Félix Samper Fuentes (1810-1877), de Madrid a París y Londres. En Estudios de Platería (Coords. J. RIVAS CARMONA e I. J. GARCÍA ZAPATA), Murcia: Universidad de Murcia, 2019, pp. 431-445.

PUERTA ROSELL, María Fernanda, Platería madrileña. Colecciones de la segunda mitad del siglo XVII, Madrid: Fundación Universitaria Española, 2005.

SÁNCHEZ CORTEGANA, José M. y MACÍAS, Rafael, Mandas testamentarias y plata labrada en Indias. Los legados de Domingo José Suárez y Juan de Salmonte y Taboada a Galicia en el siglo XVIII. En: Arte y patrimonio en España y América, Montevideo: Universidad de la República,2014, pp. 73-88.

SAN PEDRO, Fray F. de, La nada más gloriosa, sermón panegírico que en el quinto día de la infraoctava de San Bernardo predicó...este año de 1747 el M. R. P.... Sácalo a luz: D. Antonio Roserol, Platero de su Excia. Y lo dedica a D. Juan de Salmonte, y Tabuada, vecino, y del Comercio de esta Ciudad. México: Imprenta de la Viuda de D. Joseph de Hogal, 1747. 